\title{
LA RECONSTRUCCIÓN HISTÓRICA DEL ARTE COLONIAL A TRAVÉS DE SUS FUENTES GRABADAS: EL CASO DE PESSCA
}

\author{
ALMERINDO OJEDA DI NINNO \\ Pontificia Universidad Católica del Perú
}

Recibido: 16/12/2020 Aceptado: 21/12/2020

\section{RESUMEN}

El propósito de este ensayo es presentar el Proyecto para el Estudio de las Fuentes Grabadas del Arte Colonial (PESSCA), delinear las contribuciones que hace este proyecto a la catalogación, hermenéutica, ontología, restauración, reconstrucción, y recuperación del arte colonial, e ilustrar, en mayor detalle, las contribuciones que ofrece dicho proyecto a la reconstrucción virtual o histórica de obras coloniales que se encuentran demasiado dañadas para emprender su restauración. Aquí presentaremos la reconstrucción histórica de lienzos de la Catedral y de San Francisco de Quito (Ecuador) y Santa Catalina de Arequipa (Perú), de un cuero del Museum of International Folk Art de Nuevo México (Estados Unidos), y de varias pinturas murales de los estados de Hidalgo y Oaxaca (México).

Palabras clave: PESSCA, Arte Colonial, Fuentes Grabadas, Reconstrucción Histórica.

\section{ABSTRACT}

The purpose of this essay is to present the Project for the Engraved Sources of Spanish Colonial Art (PESSCA), outline the contributions this project makes to the catalogation, hermeneutics, ontology, conservation, reconstruction, and recuperation of colonial art, and to illustrate, in greater detail, the contributions this project makes to 
the virtual or historical reconstruction of colonial artworks which are too damaged to restore. Here we shall present the historical reconstruction of canvases from the Cathedral and of San Francisco de Quito (Ecuador) and Santa Catalina de Arequipa (Perú), of a hide painting of the Museum of International Folk Art of New Mexico (USA), and of several mural paintings of the States of Hidalgo and Oaxaca (México).

Keywords: PESSCA, Colonial Art, Engraved Sources, Historical Reconstruction.

\section{PRESENTACION DEL PROYECTO PESSCA}

El arte colonial fue un logro artístico asombroso. Pero también paradójico. Por un lado, fue un arte producido en las provincias más remotas de los imperios hispano-portugueses por artistas semiletrados que, en general, jamás pusieron pie en Europa. Por otro lado, sin dejar de ser sui generis, el arte colonial se ciñó, muy estrechamente, a los cánones artísticos europeos de forma y contenido ${ }^{1}$.

Afortunadamente, esta paradoja es de fácil resolución. Resulta que los artistas coloniales usaron grabados o estampas como modelos para sus composiciones ${ }^{2}$. Publicados en Amberes, París, Roma, Augsburgo, Venecia, Madrid, o Lisboa, estos grabados viajaron por millares a todo lo largo y ancho de los imperios ibéricos, dejando una marca indeleble en todas las composiciones artísticas producidas en sus territorios ${ }^{3}$.

El propósito del Proyecto para el estudio de las fuentes grabadas del arte colonial (PESSCA por sus siglas en inglés) es documentar el enorme impacto que tuvieron los grabados, mayormente europeos, sobre el arte colonial. Para alcanzar este objetivo, PESSCA ha venido identificando los grabados que sirvieron de inspiración al arte colonial, y difundiendo estas identificaciones en la página web del proyecto (colonialart.org). Lanzado en el 2005, PESSCA

1 Como ilustración, el lector podría entrar a la internet, visitar colonialart.org, e ingresar $329 \mathrm{~B}$ en el buscador de esta página. Para agilizar nuestra exposición, de ahora en adelante nos referiremos a este tipo de búsquedas escribiendo la palabra PESSCA seguida del código o palabra-clave a ingresar en el buscador. Así, si tuviéramos que referiríamos más abajo a la búsqueda anterior, diríamos simplemente "PESSCA 329B".

2 PESSCA 329A.

3 Ver OJEDA, A. "El grabado europeo como fuente del arte colonial: Estado de la cuestión." En Michaud, Cécile et al. (Eds.) De Amberes al Cvsco. El Grabado Europeo Como Fuente del Arte Virreinal. Lima, Colección Barbosa-Stern, 2009, pp. 15-21. Disponible en línea en https://colonialart.org/essays/elgrabado-como-fuente-del-arte-colonial-estado-de-la-cuestion. 
cuenta ya con más de 5000 de estas identificaciones o correspondencias, convirtiéndose así en un referente en los estudios de arte colonial. ${ }^{4}$

La documentación de las fuentes grabadas del arte colonial es un objetivo historiográfico valioso en sí mismo. Pero el interés de las investigaciones de PESSCA no se limita a esta documentación, ya que además contribuye a la catalogación, hermenéutica, ontología, restauración, reconstrucción, y recuperación del arte colonial. Veamos brevemente por qué.

En primer lugar, la página de PESSCA es un enorme repositorio de imágenes de arte colonial. Y este repositorio está claramente organizado, no sólo en términos de las fuentes del arte colonial, sino también en términos de las iconografías y ubicaciones de las obras coloniales. ${ }^{5}$ En otras palabras, PESSCA es un proyecto que podría llegar a convertirse en una suerte de catálogo razonado del arte colonial. Por otro lado, la página de PESSCA es de acceso libre y general, de modo que éste sería un catálogo razonado de acceso abierto (open access).

En segundo lugar, las investigaciones de PESSCA nos permiten interpretar obras de arte coloniales con contenidos oscuros o confusos. O corregir interpretaciones erróneas de las mismas. Esto es porque los grabados que inspiraron tales obras pueden tener iconografías más completas. O pueden estar acompañados de leyendas — es decir textos que explicitan las escenas representadas o identifican plenamente a los personajes que las pueblan. Un buen ejemplo de este uso de PESSCA se ve en una hermosa pintura cusqueña que muestra a una mujer gesticulante colocada entre otras cinco mujeres y un altar sobre el que se muestra el Santísimo. ${ }^{6}$ La desconcertante iconografía de esta pintura se aclara cuando consideramos el grabado en el que se basó. Se trata de un grabado de Cornelis Galle I (1575-1650) que lleva al pie la leyenda proestet fides supplementum sensuum defectui 'que la fe suplemente las deficiencias de los sentidos' — verso del himno eucarístico Pange Lingua compuesto por Santo Tomás de Aquino para la entonces joven fiesta del Corpus Christi. ${ }^{7}$ La mujer gesticulante representa, pues, a La Fe; las otras mujeres, a Los Cinco Sentidos. La pintura muestra a la fe llevando a los sentidos hacia la recta comprensión de la Eucaristía.

4 Para seguir la trayectoria de este proyecto, el lector puede visitar colonialart.org y pulsar sobre la pestaña News.

5 Para apreciar la organización del material de PESSCA, ingresar a colonialart.org y pulsar sobre la pestaña Archives.

6 PESSCA 3065B.

7 PESSCA 3065A. 
En tercer lugar, la confrontación de las obras de arte coloniales con sus fuentes grabadas nos ofrece la posibilidad de identificar la originalidad o autonomía del arte colonial; su contribución específica a la historia del arte universal. Y nos permite hacerlo de manera objetiva, evitando sesgos, tanto europeístas como indigenistas, que han dificultado, en el pasado, la discusión de la autonomía del arte colonial. Buen ejemplo de este uso de los hallazgos de PESSCA es la serie de correspondencias que entabla un estupendo cuadro firmado en 1767 por el pintor novohispano Miguel Cabrera (1695-1768). ${ }^{8}$ Nos referimos al Regina Angelorum que se encuentra hoy en la Catedral Metropolitana de la Ciudad de México. Las correspondencias en cuestión establecen que Cabrera basó su composición en dos grabados bávaros del siglo XVIII: una Mater Creatoris (grabado al buril del Taller Klauber) y una Adoración del Sagrado Corazón, (grabado a la mediatinta del Taller Pfeffel). Para conseguir esto, Cabrera colocó la imagen de Klauber al centro de la composición de Pfeffel, reemplazando así un Sagrado Corazón por una Virgen María. Aparte de sintetizar dos composiciones en una, Cabrera tuvo que traducir el lenguaje gráfico de los grabados al lenguaje pictórico de su cuadro. Además le cambió el nombre a la Mater Creatoris del grabado de Klauber, llamándola Regina Angelorum. Probablemente hizo esto porque ésta se verá rodeada de los ocho ángeles que Cabrera tomaría del grabado de Pfeffel. Cabrera además transformó las poses y las posiciones de estos ángeles. Así, cambió por completo el tema del grabado de Pfeffel, transformándolo, de una adoración Corazón de Jesús, a una glorificación de una Reina de los Ángeles.

En cuarto lugar, el trabajo de PESSCA apoya la conservación o restauración de obras de arte colonial, sea guiando las intervenciones materiales en obras de arte colonial, o corrigiendo restauraciones confusas o excesivas. Como ejemplo de este uso de PESSCA podemos ofrecer la correspondencia PESSCA 3316A/3316B. En la pintura que forma parte de esta correspondencia vemos, en la esquina inferior izquierda, un semicírculo de monedas que no cuadra con la iconografía antoniana. Afortunadamente, si consultamos el grabado en el que se basó esta pintura veremos que la figura correspondiente es un insecto infernal de cola articulada. Tal insecto, en cuanto criatura infernal, cuadra perfectamente con la iconografía antoniana. Y es probable que esta cola articulada fuera erróneamente interpretada como un semicírculo de monedas por el restaurador.

En quinto lugar, PESSCA nos permite reconstruir, aunque sea en la imaginación, obras de arte coloniales que están extraviadas, robadas, destruídas, o demasiado deterioradas como para ser materialmente restauradas. Es a este tipo

8 PESSCA 4500A/4500B. 
de reconstrucción histórica —o restauración virtual - al que nos dedicaremos en la segunda parte de este trabajo. De momento, consignaremos aquí que esta función de PESSCA es especialmente importante cuando las obras reconstruidas se perdieron (o se dañaron irremediablemente) antes de haber sido fotografiadas. En estos casos, la contemplación de las fuentes grabadas de las obras perdidas podría ser la mejor manera — si no la única- de rescatarlas del olvido.

En sexto lugar, PESSCA puede contribuir - y de hecho ha contribuido yaa la recuperación material de obras extraviadas o robadas. Una vez más, esta función de PESSCA es especialmente valiosa cuando las obras a recuperar desaparecieron antes de haber sido fotografiadas. Un buen ejemplo de esta contribución se refiere a una conocida serie de pinturas sobre el Zodíaco del pintor cusqueño Diego Quispe Tito (1611-1681). Como cabría esperar, la serie debió contener doce pinturas. Sin embargo, de estas doce, sólo se sabe de nueve, suponiéndose que las tres restantes han sido sustraídas. ${ }^{9}$ Afortunadamente, conocemos las fuentes grabadas de toda esta serie. ${ }^{10}$ Incluidas las de las tres sustraidas. Por tanto, es posible formarse una idea bastante clara de las pinturas hoy desaparecidas. Y con esta idea, intentar ubicar y recuperar las pinturas robadas.

Para mayores detalles, invitamos al lector a consultar la página web del proyecto, ubicada, como ya se dijo, en colonialart.org. Además de la sección de archivos en la que se puede examinar la organización de las correspondencias de PESSCA, y además de la sección de galerías en las que se puede ver la serie cusqueña de pinturas del Zodíaco, la página web de este proyecto ofrece una bibliografía especializada, una serie de ensayos pertinentes, y una gran cantidad de enlaces a repositorios digitales, tanto de grabados como de obras de arte colonial. Con estos recursos el proyecto busca facilitar la colaboración internacional para la investigación de las fuentes grabadas del arte colonial.

\section{PESSCA Y LA RECONSTRUCCIÓN HISTÓRICA DEL ARTE COLONIAL}

El Templo de San Francisco de Quito contiene una estupenda serie de lienzos adheridos a su sotocoro. Aunque la mayoría de estos lienzos está en buen estado de conservación, hay uno que tiene una pérdida significativa en la

9 Estas nueve pinturas se encuentran hoy en el Museo de Arte Religioso del Palacio Arzobispal del Cusco.

10 Ingresar a colonialart.org, pulsar sobre la pestaña Galleries, y visitar la Galería 4: La Serie del Zodiaco. 
zona central de la composición. Y esta pérdida hace imposible apreciar (si no identificar) el tema del mismo. Afortunadamente, sabemos que las pinturas de este sotocoro conforman una serie del Génesis. Lo que es más, sabemos que estas pinturas derivan de las ilustraciones grabadas de una Biblia flamenca de fines del siglo XVI: el Thesaurus Sacrarum Historiarum Veteris Testamenti, publicada por Gerard de Jode (1509/17 - 1591) en Amberes en 1585. Y es el hallazgo de esta fuente lo que nos permite identificar - y apreciar - el tema de nuestro lienzo. Se trata de Las Ofrendas de Abel. ${ }^{11}$

El presbiterio del templo agustino de Todos los Santos de Zempoala (Hidalgo, México) despliega un ciclo de pinturas murales. Las pinturas son del primer siglo de la colonia, y se basan en una serie de xilografías de Erhard Schoen (ca. 1491-1542) publicadas en Lyon y Nuremberg a partir de 1518. Todas las pinturas murales del ciclo pictórico de Zempoala están dañadas. Algunos de estos daños son importantes, y dificultan la interpretación de los temas representados. Quizás la más dañada de éstas sea una pintura que representa los bordes de una edificación sobre la cual el Padre Eterno nos bendice. Difícil sería identificar el tema de esta composición si no supiéramos que la serie se basa en las ilustraciones de la Biblia de Schoen. Buscando entre ellas descubrimos la fuente de la pintura dañada, y sólo así logramos identificar su tema. Se trata de La visión de Isaías del trono celestial (Isaías 6). ${ }^{12}$

El Museum of International Folk Art, ubicado en Santa Fe, Nuevo México (EEUU) alberga una rara pintura sobre cuero que en la actualidad muestra superficies pigmentadas cuyos perímetros no nos permiten discernir figuras. La pintura es de un artista local no identificado del siglo XVIII, y conocido hoy solamente como el Maestro de la Basta Ondulada (Wavy Hem Painter). Afortunadamente, el ojo acucioso de la investigadora norteamericana Kelly Donohue-Wallace logró ver, en las superficies pigmentadas de esta pintura, a un Cristo Niño Salvador del Mundo. ${ }^{13}$ Lo que es más, consiguió establecer que esta imagen proviene de un grabado de Paulus Pontius (1603-1658) tras van Dyck. ${ }^{14}$

El Portal de Peregrinos del Ex-Convento agustino San Nicolás Tolentino, ubicado en Actopan, Hidalgo (México), muestra una curiosa pintura mural que parece ilustrar un galeón sobre cuya verga se tiende un agustino. La pintura, sin embargo, tiene graves pérdidas que afectan la totalidad del casco de la nave y

11 PESSCA 2100A/2101B.

12 PESSCA $1726 \mathrm{~A} / 1726 \mathrm{~B}$.

13 DONAHUE-WALLACE, K. "The print sources of New Mexican colonial hide paintings." Anales del Instituto de Investigaciones Estéticas, Volumen 68, 1996, pp. 43-69.

14 PESSCA 1398A/1398B. 
sus alrededores. Fue el maestro Santiago Sebastián quien dio con el grabado que sirvió de modelo a esta pintura. ${ }^{15}$ Se trata de un aguafuerte de Natale Bonifacio da Sebenico (1537-1592) publicado en Roma en 1582: La Nave Agustina ${ }^{16}$ Gracias a esta correspondencia podemos interpretar esta notable analogía de la orden agustina, que Santiago Sebastián describe así:

La vemos [a la nave agustina] llegando al puerto del Paraíso, con Santa Mónica a la proa enarbolando la cruz, y al timón a su hijo Agustín, mientras que puede ser San Nicolás Tolentino el fraile tendido sobre el palo perpendicular al mástil. Van sobre la cubierta tres virtudes, por ello se la considera como nave teológica. Al llegar a las playas del Paraíso salen a recibirla el Padre Eterno y el Espíritu Santo, que dispara las flechas de su divina sabiduría sobre el corazón del Obispo de Hipona; al Hijo lo vemos crucificado en el Árbol de la Vida, mientras arroja sangre de su costado en una taza, a la que llegan los monjes por medio de los sacramentos (SEBASTIÁN, S. Iconografía e iconología del arte novohispano. México D.F., Grupo Azabache, 1992, p. 67).

Casi nada de esta interpretación habría sido posible si no contáramos con el grabado de Sebenico.

Otro hallazgo pertinente de Santiago Sebastián se refiere a una de las pinturas murales del cubo de la escalera del Convento de San Agustín de Atotonilco el Grande, Hidalgo, México. ${ }^{17}$ La pintura en cuestión, que data del siglo XVI, muestra a San Agustín rodeado por seis filósofos paganos de la Antigüedad: Séneca, Sócrates, Platón, Aristóteles, Cicerón, y Pitágoras. Cada uno de estos filósofos está asociado a una máxima que ha llegado muy dañada a nuestros días. Afortunadamente, el maestro Sebastián dio con la fuente grabada de esta pintura. Se trata de la portada xilografiada del Decem Librorum Moralium de Aristóteles, en edición parisina publicada por Simon de Colines en $1535 .{ }^{18}$ Este feliz hallazgo nos permite reconstruir —y, lo que es más, interpretar - los textos dañados en la pintura mural de Atotonilco el Grande. Encorchetando el material reconstruído gracias al hallazgo de la fuente grabada, ahora podemos leer:

15 SEBASTIÁN, S. "Libros hispalenses como clave del programa iconográfico de la escalera de Actopan (México)." Revista de Arte Sevillano, Volumen 2, 1982, 67.

16 PESSCA $1345 \mathrm{~A} / 1345 \mathrm{~B}$.

17 SEBASTIÁN, S. "Fuentes iconográficas del programa de Atotonilco." Arte y Arquología, Vols. 5-6, 1978, pp. 181-184. Ver también MONTERRUBIO, A. L. Conventos agustinos en Hidalgo. Convento de San Agustín, Atotonilco el Grande. Convento de San Andrés, Epazoyucan. Pachuca, Dirección General de Publicaciones e Impresos del Gobierno del Estado de Hidalgo, 2012, pp. 84-91.

18 PESSCA 1466A/1466B. 
Séneca: [NUNQUAM] STYIGIAS FER TUR AD V[M]BRAS INCLYTA VIR[TUS]

'La virtud ínclita nunca lleva a las sombras infernales.'

Sócrates: ADOLESCE[N]TES SPECULUM CO[N]SULANT QVO AD BONUM INCITE[N]TUR

'Los jóvenes miran al espejo para esforzarse al bien.'

Platón: BREBES VIRTUTIS [L]ABORES ETERNA VOLVPTAS SEQUITUR

'Los trabajos de la virtud son breves, de ellos sigue el eterno placer.'

Aristóteles: NO[N] DE VIRTVT[E SCIRE S]AT EST SED ENITENDUM EST IPSAT [HAB]ERE

'No es suficiente conocer la virtud, sino esforzarse por poseerla.'

Cicerón: QVI VIRTVTE [PREDITI] SUNT SOLI SVNT [DIV]ITES

'Solamente son ricos los que están llenos de virtud.'

Pitágoras: STATERAM NE [TRA]NSGREDIAR[E ID EST] VIRVTIS MEDIV[M NE] $\mathrm{T}[\mathrm{R}] \mathrm{AN}[\mathrm{SGR}] \mathrm{EA}[\mathrm{S}]$

'No inclinar el fiel de la balanza: esto es, no traspases el medio de la virtud.'

El Convento de Santa Catalina de Arequipa alberga una serie de lienzos que representan a cinco Reyes de Judea sentados sobre las ramas de un árbol. Como podría esperarse, se trata del árbol de Jesé. Pero esta serie de lienzos está incompleta. Por suerte hemos podido determinar que estos lienzos provienen de un marco ornamental grabado por Cornelis Galle I, diseñado originalmente por Rubens y eventualmente usado para adornar la portada de un Misale Romanum de $1650 .{ }^{19}$ Gracias a esta determinación podemos confirmar la interpretación en términos del árbol de Jesé, identificar a las figuras faltantes, e imaginar así los lienzos de los siete reyes faltantes en la serie arequipeña.

En el Ex-Convento dominicano de Santiago Apóstol de Cuilapan, Oaxaca (México) se conservan un par de portadas interiores adornadas con marcos inspirados en las páginas titulares de dos secciones de un conocido manual de caligrafía del siglo XVI —el Arte Subtilissima por el cual se enseña a escriuir correctamente, compuesto por Juan de Yciar (1525-1575) y publicado por primera vez en Zaragoza en 1550. Este par de portadas conventuales sigue puntualmente a las portadas impresas de la obra de Yciar, incluso adoptando una coloración a la grisalla que sigue muy de cerca el acromatismo de su modelo

19 PESSCA 1781A/1781B - 1784A/1784B, 2714A/2714B. 
libresco, resultado de la impresión, en tinta negra, sobre papel blanco. ${ }^{20}$ Ahora bien, además de estas dos portadas, el ex-convento oaxaqueño conserva una tercera portada, la cual, a diferencia de las dos primeras, se encuentra muy dañada, reduciéndose en realidad a dos pequeños fragmentos. Pero resulta que esta portada también deriva de una de la portada de una de las secciones del mismo manual que las anteriores- la sección que trata de La Letra Cancilleresca..$^{21}$ Así nos enteramos que los fragmentos no son sino el extremo derecho de una cariátide que ocurre, en imagen de espejo, al otro lado de la portada. Estas cariátides a su vez sostienen ménsulas sobre las que descansan sendas volutas. De estas ménsulas penden también borlas, en cuyos cordones se enroscan serpientes.

En su Historia de la Cultura Ecuatoriana, ${ }^{22}$ fray José María Vargas nos informa que

Para la erección del túmulo [funerario a la muerte de la reina Margarita de Austria] en la catedral [de Quito en 1613], el corregidor don Sancho Díaz de Zurbano hizo comparecer a los pintires de Quito y les encomendó que en cuadros de tamaño natural trasladasen los retratos de los antepasados de Felipe II, a partir de Pipino I, duque de Brabancia. Los originales se contenían en grabados que compuso Juan Bautista Urientino de Antuerpia. Resultaron "los traslados semejantes a sus originales, con los vestidos y ropajes, que cada uno en su tiempo usaron tan al vivo y tan perfectos y acabados, que son los mejores cuadros que hay en este Reino" (Vargas cita aquí del documento Archivo General de Indias 76-6-10.-V.G. Col. 4a serie, vol. 18, p. 394).

Se desconoce el paradero de todos estos cuadros (si es que aún sobreviven). Afortunadamente podemos reconstruirlos, al menos en nuestra imaginación, si tenemos a la vista los grabados de Jan Collaert II (1556-1625) diseñados por Otto van Veen (1556-1629) y publicados por el mentado Juan Bautista Urientino de Antuerpia — es decir Johannes Baptista Vrintz I (1547-1616). ${ }^{23}$

Concluimos, pues, de estos ejemplos que el estudio de las fuentes grabadas del arte colonial en efecto nos permite reconstruir, aunque sea en la imaginación, obras de arte coloniales que están extraviadas, robadas, destruídas, o demasiado deterioradas como para ser materialmente restauradas.

20 PESSCA 2239A/2239B, PESSCA 2240A/2240B. Estas correspondencias fueron descubiertas por ESTRADA DE GERLERO, E. I. Muros, sargas y papeles. Imagen de lo sagrado y lo profano en el arte novohispano del siglo XVI. Ciudad de México, Instituto de Investigaciones Estéticas, 2011, p. 553.

21 PESSCA 2241A/2241B.

22 VARGAS O.P., J. M. Historia de la cultura ecuatoriana. Quito, Casa de la Cultura Ecuatoriana, 1965, p. 157.

23 PESSCA 5050A/5050B. 


\section{BIBLIOGRAFÍA}

DONAHUE-WALLACE, K. "The print sources of New Mexican colonial hide paintings." Anales del Instituto de Investigaciones Estéticas, Volumen 68, 1996, pp. 43-69.

ESTRADA DE GERLERO, E. I. Muros, sargas y papeles. Imagen de lo sagrado y lo profano en el arte novohispano del siglo XVI. Ciudad de México, Instituto de Investigaciones Estéticas, 2011.

MONTERRUBIO, A. L. Conventos agustinos en Hidalgo. Convento de San Agustín, Atotonilco el Grande. Convento de San Andrés, Epazoyucan. Pachuca, Dirección General de Publicaciones e Impresos del Gobierno del Estado de Hidalgo, 2012.

OJEDA, A. Project for the Engraved Sources of Spanish Colonial Art (PESSCA). Página web ubicada en https://colonialart.org y en https://artecolonial.pucp.edu.pe, 2005-2020.

OJEDA, A. "El grabado europeo como fuente del arte colonial: Estado de la cuestión." En Michaud, Cécile et al. (Eds.) De Amberes al Cvsco. El Grabado Europeo Como Fuente del Arte Virreinal. Lima, Colección Barbosa-Stern, pp. 15-21, 2009. Disponible en línea en https://colonialart.org/essays/el-grabado-como-fuente-del-arte-colonialestado-de-la-cuestion.

SEBASTIÁN, S. "Fuentes iconográficas del programa de Atotonilco." Arte y Arquología, Vols. 5-6, 1978, pp. 181-184.

SEBASTIÁN, S. "Libros hispalenses como clave del programa iconográfico de la escalera de Actopan (México)." Revista de Arte Sevillano Volumen 2, 1982.

SEBASTIÁN, S. Iconografia e iconología del arte novohispano. México D.F., Grupo Azabache, 1992.

VARGAS O.P., J. M. Historia de la cultura ecuatoriana. Quito, Casa de la Cultura Ecuatoriana, 1965.

Almerindo Ojeda Di Ninno

Profesor Emérito, Universidad de California (Davis), y Profesor Honorario, Pontificia Universidad Católica del Perú. https://orcid.org/0000-0002-3396-0150 aeojeda@ucdavis.edu 